\title{
SOBRE A EPISTEMOLOGIA DA FORMAÇÃO DE PROFESSORES
}

\author{
SOBRE LA EPISTEMOLOGÍA DE LA FORMACIÓN DE PROFESORES
}

ABOUT THE EPISTEMOLOGY OF TEACHER EDUCATION

\author{
Ivan FORTUNATO ${ }^{1}$ \\ Juanjo MENA ${ }^{2}$
}

\begin{abstract}
RESUMO: Este artigo de abertura do número especial sobre epistemologia e formação de professores busca apresentar um panorama parcial da área. Elaborado na forma de um ensaio, o objetivo é descrever algumas teorias que têm norteado a formação docente, inicial e continuada, a partir de práticas vivenciadas em territórios distintos. Não se trata de um estudo comparado, pois não se analisam as diferenças ou proximidades. $\mathrm{O}$ objetivo principal é refletir sobre o suporte epistemológico, consistente e/ou emergente, que tem embasado normas, formas e metodologias de formação de professores. Ao final, espera-se colocar em evidência a epistemologia como algo fundante da carreira docente, a qual deve ser revisitada amiúde por aqueles que são responsáveis pela formação de professores.
\end{abstract}

PALAVRAS-CHAVE: Formação docente. Teoria educativa. Prática docente.

RESUMEN: Este artículo de apertura del número especial sobre epistemología y formación de profesores busca presentar un panorama parcial del área. El objetivo es describir algunas teorías que han orientado la formación docente, inicial y continua, a partir de prácticas docentes que se han llevado a cabo en territorios distintos. No se trata de un estudio comparado, pues no se analizan las diferencias o similitudes en la práctica profesional. El objetivo principal es reflexionar sobre el apoyo epistemológico, consistente y/o emergente, que ha fundamentado normas, formas y metodologías de formación de profesores. Al final, se espera poner en evidencia la epistemología como algo fundante de la carrera docente, la cual debe ser revisada concienzudamente por aquellos que son responsables de la formación de profesores.

PALABRAS-CLAVE: Formación docente. Teoría educativa. Práctica docente.

ABSTRACT: This opening article of the special issue on epistemology and teacher training seeks to present a partial overview of the area. Elaborated as an essay, the objective is to describe some theories that have guided initial and continuing teacher education, based on practices lived in different territories. This is not a comparative study because the differences or proximity are not analyzed. The main objective is to reflect on the consistent and / or emergent epistemological support that has been based on norms,

${ }^{1}$ Instituto Federal de São Paulo (IFSP), Itapetininga, SP, Brasil. Coordenadoria de Formação Pedagógica. ORCID <https://orcid.org/0000-0002-1870-7528>. E-mail: ivanfrt@ yahoo.com.br

${ }^{2}$ University of Salamanca (USAL, Spain). Department of Education. ORCID <https://orcid.org/0000-00026925-889X>. E-mail: juanjo_mena@usal.es 
forms and methodologies of teacher training. In the end, it is hoped to highlight epistemology as a founding of the teaching career, which should be revisited often by those who are responsible for teacher training.

KEYWORDS: Teacher education. Educational theory. Teaching practice.

Epistemologia: é a ciência da ciência. Filosofia da ciência. É o estudo crítico dos princípios, das hipóteses e dos resultados das diversas ciências. É a teoria do conhecimento (TESSER, 1995, p. 92).

Este artigo de abertura do número especial sobre epistemologia e formação de professores busca apresentar um panorama parcial da área. Pensar na epistemologia equivale a pensar sobre os fundamentos de determinado campo do conhecimento. De certa forma, um exame epistemológico envolve profunda análise do que se sabe e, portanto, do que se está fazendo. Aqui, não pretendemos enveredar pela etimologia da palavra, tampouco pela evolução histórica do conceito, o qual é objeto de estudos da filosofia e da filosofia das ciências (ABBAGNANO, 2007; JAPIASSU, 1988), assumindo, dessa forma, significados múltiplos em diferentes contextos. Elaborado na forma de um ensaio, o propósito deste artigo é tomar a epistemologia como um conceito que implica conhecer o conhecimento e, assim, realizar uma incursão por algumas das ações vivenciadas na e para formação docente que são realizadas em dois territórios distintos.

Um deles se passa no Brasil, mais especificamente no sudoeste paulista, nos cursos de formação inicial e de especialização de professores do Instituto Federal de São Paulo (IFSP), campus de Itapetininga. O outro, na Espanha, na Universidade de Salamanca (USAL), nos programas de formação docente para professores, oferecidos pela Faculdade de Educação. Não se trata de um estudo comparado, pois não se analisam as diferenças ou proximidades entre o que fazemos no Brasil e na Espanha. O objetivo principal é refletir sobre o suporte epistemológico, consistente e/ou emergente, que têm embasado normas, formas e metodologias de e para a formação de professores. Ao final, depois de tratar de particularidades de nossa experiência, travamos breve diálogo com as propostas contidas neste dossiê. Espera-se, assim, colocar em evidência a epistemologia como algo fundante da carreira docente, a qual deve ser revisitada amiúde por aqueles que são responsáveis pela formação de professores.

A esse respeito, Romanowski (2013) recuperou a história da formação de professores, retornando à criação da Escola Normal que, no Brasil, foi institucionalizada 
no final do século XIX. A autora anotou que a primeira preocupação da pós-graduação brasileira com a formação de professores pode ser evidenciada por uma dissertação defendida em 1987. Desde esse ano, identificou um número crescente de teses e dissertações que versam sobre o tema, tratando a respeito dos cursos de formação, de análises curricular e documental a diagnósticos empíricos a respeito de cursos específicos; teses e dissertações do tipo estado da arte, mapeando as mais variadas formas de se pensar a formação docente; e trabalhos de intervenção, nos quais os pesquisadores imergem em uma escola ou propõem cursos de formação continuada. Esses estudos alcançaram expressivos $12 \%$ do total de toda produção da pós-graduação nacional em educação, evidenciando a importância do campo de formação de professores.

Diniz-Pereira (2013) remontou a história do campo de formação docente no Brasil, iniciando seu percurso na década de 1970, momento em que havia enfoque técnico e comportamental da educação, sendo o professor "um organizador dos componentes do processo de ensino-aprendizagem" (p. 146). Da crítica à racionalidade técnica, o enfoque da formação de professores passou a ser, ainda na década de 1970, práticas de transformação social, econômica e política. Esse enfoque perdurou até a transição para os anos 1990, quando se passou a conceber o professor como um profissional reflexivo, o qual deveria se tornar um pesquisador na ação. Na entrada deste século, expõe o autor, a identidade docente e a profissionalização passaram a ser objetos centrais da formação de professores.

Nessa mesma direção, Cunha (2013) também apontou alguns caminhos para a construção do campo da formação de professores. A autora começou por delinear esse campo como um tripartido que envolve a pesquisa, a prática e a própria concepção social de professor. De imediato, concebeu a formação como algo que não é neutro nem puramente técnico, mas subjetivo, estabelecido em um continuum desde os processos de educação não formal - o qual estamos todos imersos quando vivemos em sociedade -, passando pelo curso universitário de licenciatura, até o envolvimento cotidiano com a profissão e seus desafios contextuais. No artigo, Cunha (2013) recuperou a trajetória da área de formação de professores no Brasil, recuando aos anos 1960, avançando até final da primeira década dos anos 2000, na qual delineou diversas tendências que marcaram a formação docente no país. Segundo a autora, estamos num momento em que a tendência na formação de professores é a de narrativas culturais e desenvolvimento profissional, caracterizada por estudos nos quais "o professor age com base nos saberes estruturais, provenientes de diferentes fontes e contextos. Constrói seus saberes a partir das múltiplas 
influências de formação, em cotejamento com o contexto cultural e institucional onde atua" (p. 620).

Ao recuar ao ano de 2014, momento de ingresso na atividade de formar professores no IFSP de Itapetininga, parece que essas tendências delineadas por Diniz-Pereira (2013) e por Cunha (2013) não foram as escolhidas para o desenvolvimento de disciplinas referentes à didática e prática docente. Em início de carreira, sem saber ao certo como lidar com essa responsabilidade de trabalhar com a formação docente, o uso da bibliografia nacional clássica, como Piletti (2004), Libâneo (1994) e Pimenta (2000) foram as opções mais "seguras" para a condução das aulas catedráticas, pois a notoriedade desses autores conferiam credibilidade para o trabalho teórico realizado. Na década de 1960, Füller (1969) já havia delineado como se constrói a carreira docente, sendo que esse autor identificou que as preocupações iniciais do professor são quase sempre voltadas para uma espécie de "sobrevivência" na carreira. Para o autor, nessa busca pela sobrevivência, quase toda energia desprendida tem como foco dominar o conteúdo, controlar a classe, além de buscar por uma autoafirmação de que se é, efetivamente, professor.

O que Füller (1969) descreveu como um desenvolvimento natural da carreira, curiosamente somente pode ser alcançado depois que o próprio autor o evidenciou: as preocupações centradas no estudante e no seu aprendizado. Isso quer dizer que sem as ponderações do autor norte-americano, não teria sido possível perceber que as atividades desenvolvidas para formação docente no IFSP, nas disciplinas de didática e prática docente, estavam centradas apenas no docente responsável por elas. Embora estivessem ancoradas em textos clássicos, pode-se dizer que esse lastro era como um porto seguro para quem estava vivendo as preocupações iniciais de sobreviver na carreira. Contudo, não estavam presentes nas aulas de formação de professores as tendências mais atuais, centradas na identidade docente e na profissionalização (DINIZ-PEREIRA, 2013), e/ou nas narrativas culturais (CUNHA, 2013).

Foram alguns semestres de trabalho catedrático, até a percepção de que toda diligência estava configurada a partir da sobrevivência na carreira, sem qualquer preocupação com o aprendizado efetivo dos futuros professores. Assim, pela elucidação de Füller (1969), outros suportes precisaram ser incorporados, particularmente aqueles que tratavam com propriedade o cotidiano docente. Isso não quer dizer que o baldrame da teoria clássica não fosse importante para a formação docente, mas, insuficiente. A primeira ação tomada foi a procura de uma bibliografia consistente com a prática cotidiana de 
professores, que pudesse colaborar não apenas com a compreensão mais realista da atividade docente, mas com a própria construção da identidade e dos desafios da profissão.

Dentre outros, a pujante obra de Célestin Freinet foi tomada como sólido baldrame para o trabalho com futuros professores, pois nela existem contundentes críticas à educação escolar de massas, além de frutífero desenvolvimento de uma teoria e de práticas educativas consolidadas pelo efetivo exercício da docência nas escolas. Todo o suporte dado por Freinet pode ser lido em outros ensaios, nos quais suas duras críticas e prodigiosas práticas educativas são evidenciadas como suporte à formação contemporânea de professores, especialmente pelas suas ideias de vanguarda a respeito da educação (FORTUNATO, 2018; 2017; 2016a; 2016b; FORTUNATO, CUNHA; TEMPLE, 2017; CUNHA, FORTUNATO, 2017).

Na busca pela evolução da forma de trabalho com a formação docente, as aulas catedráticas foram tomando novos rumos a partir de Freinet, e o campo concreto de atuação dos futuros professores foi sendo mapeado, reconhecido e incorporado no processo formativo. Assim, as aulas de formação docente não eram mais apenas compostas pelo estudo da teoria clássica sobre didática e prática docente, e sua respectiva assimilação por meio de leituras, seminários e resenhas. Isso porque a visitação e o desenvolvimento de práticas de intervenção em distintos cotidianos educativos (escolas de ensino fundamental e médio, institutos de educação técnica, organizações não governamentais, o presídio) passaram a compor o rol de atividades formativas. Algumas dessas iniciativas foram partilhadas em outros textos, os quais ajudam a compreender melhor como a presença no campo de atuação docente, durante os processos de formação inicial, potencializa a construção da identidade profissional e permite uma visão mais ampla, complexa e reflexiva do que significa ser professor (FORTUNATO, 2018b; 2018c; FORTUNATO; FALCHI, 2018).

Já na Espanha, embora existam algumas instituições responsáveis pela formação de professores antes do século XIX (por exemplo, Escolas Normais e a Cátedra de Educação), nesse referido século é que foi criada a primeira referência de formação, a Escola Central de Professores. A missão dessa instituição era buscar uma educação regulamentada e um currículo unitário para todo o país. Essa instituição foi base para criação de outras que, mais tarde, ficaram conhecidos como as Escolas Normais de Formação de Professores (ANGUITA, 1997), que duraram até um pouco mais do que a metade do século XX.

Segundo Anguita (1997), existiam cinco características da formação de professores nesse período: (1) uma abundância de legislação, já que os governos da época queriam 
controlar o que os futuros professores aprendiam, pois, no final, eles estariam encarregados de aplicar as reformas educacionais; (2) a influência da Instituição Livre de Educação no final do século XIX e início do século XX, que nos fez refletir sobre as novas concepções pedagógicas da educação; (3) a influência do poder religioso na inclusão de aspectos da moralidade cristã (exceto no período da república: 1931-1939); (4) baixo perfil do currículo de formação em relação a outras profissões: o currículo centra-se na aprendizagem da língua oficial do estado, gramática e aritmética, geografia, história e moralidade; (5) baixa formação profissional em oposição à formação culturalista.

No que diz respeito aos programas de formação de professores da Universidade de Salamanca (USAL), esses se resumem em três: formação de professores de educação infantil, ensino primário e ensino secundário. Os dois primeiros são programas concomitantes, enquanto o segundo é um programa consecutivo.

Os programas concomitantes oferecem uma formação profissional tanto disciplinar quanto pedagógica, em conteúdos teóricos e práticos. Os modelos concomitantes tendem a ser predominantes na formação inicial de professores. Esses programas fornecem formação teórica em termos de conteúdo acadêmico (tanto disciplinar quanto pedagógico) e conteúdo profissional (focado na prática de ensino nas escolas). Sob esses modelos, o conteúdo dos programas de formação inicial docente é oferecido de maneira integrada. Em particular, na Espanha, os cursos de formação de professores têm quatro anos de duração (anteriormente eram três anos nos cursos de licenciatura).

Nos programas consecutivos, os formandos têm que estudar primeiro as disciplinas específicas do campo acadêmico (por exemplo, geografia, matemática, música etc.) e, num segundo momento, estudar os temas pedagógicos, além de um período de estágio na escola. Muitos países, especialmente no ensino secundário, são organizados em modelos consecutivos, como na Holanda, Irlanda, Espanha e Portugal (MENA, 2017).

Nos dois tipos de programas, a capacitação profissional destaca as habilidades teóricas e práticas necessárias para ser um professor. Essa capacitação inclui práticas nas escolas. Essas práticas são remuneradas em alguns dos referidos países europeus (em outros não), e geralmente duram algumas semanas sob a supervisão de um professor especialista. Os dois tipos de programas têm vantagens e desvantagens quando se trata de encaixá-los nos currículos das instituições de ensino superior. No entanto, nos últimos anos, tem havido uma tendência para aumentar a duração dos programas de formação, bem como para aumentar seus critérios em toda a Europa, fundamentalmente devido à reforma do Espaço Europeu de Educação Superior (LADD, 2007).

RIAEE - Revista Ibero-Americana de Estudos em Educação, Araraquara, v. esp. n. 2, p. 1881-1895, dez., 2018. E-ISSN: $1982-5587$. 
O estágio curricular supervisionado (practicum), em todos os programas, tem uma relevância especial. O estágio é o período das práticas profissionais realizadas pelos professores em formação durante a carreira universitária (MENA; RODRÍGUEZ; HUBBAL; CLARKE, 2014). Vários autores sublinharam a importância de oferecer contextos práticos no processo de formação inicial (ZEICHNER, 2010). O estágio, disciplina obrigatória para a formação de um professor, oferece um espaço de capacitação dentro das escolas, em que o professor em formação tem a possibilidade de enfrentar problemas reais, experimentando situações diversas, podendo cotejar as teorias com a ação docente. De certa forma, é um período que permite “[...] selecionar, organizar e elaborar as informações que lhe permitam evoluir no planejamento e desenvolvimento de seu trabalho profissional como professor" (AZCÁRATE, 1997, p. 107).

O estágio é a ação que o professor em formação desenvolve na sala de aula, e diz respeito ao processo de ensino. Entre seus recursos mais característicos está o fato de ser uma prática que ocorre em um determinado tempo e espaço e, portanto, pode ser submetida a análises sucessivas, que nos permitem investigar, analisar ou transformar o que é feito dentro de um contexto particular (IMBERNON, 1997). Portanto, essa primeira experiência profissional do professor em formação é construída pela reelaboração e combinação dos diferentes conhecimentos obtidos no curso universitário, sendo reformulada com base na formação acadêmica obtida. Tudo isso é o que constitui, no final, o conhecimento profissional (MENA; CLARKE, 2015; MENA; HENNISSEN; LOUGHRAN, 2017).

O estágio, nos programas de formação de professores para o ensino pré-escolar e primário, consiste em duas disciplinas: Practicum I e Practicum II. Estas disciplinas têm uma parte teórica e uma parte prática desenvolvida nas escolas, com duração de sete semanas, na Practicum I, e nove semanas, na Practicum II (GUÍA DEL PRÁCTICUM, 2018a). Nesse período, os professores em formação fazem uma estadia nas escolas de Educação Infantil e Primária. De acordo com os regulamentos em vigor, os módulos do Practicum para o grau de Educação Primária apresentam uma série de competências específicas (Anexo da Ordem ECI / 3857/2007), sendo:

1. Adquirir um conhecimento prático da sala de aula e da sua gestão.

2. Conhecer e aplicar os processos de interação e comunicação em sala de aula e dominar as habilidades e competências sociais necessárias para promover um clima de sala de aula que facilite o aprendizado e a convivência. 
3. Controlar e monitorizar o processo educativo e, em particular, o processo de ensino-aprendizagem, dominando as técnicas e estratégias necessárias.

4. Relacionar teoria e prática com a realidade da sala de aula e de uma instituição de ensino.

5. Participar da atividade de ensino e aprender a fazer, agir e refletir a partir da prática.

6. Participar das propostas de melhoria nas diferentes áreas de ação que podem ser estabelecidas em uma instituição de ensino.

7. Regular os processos de interação e comunicação em grupos de alunos de 3 a 6 e de 6 a 12 anos.

8. Conhecer formas de colaboração com os diferentes setores da comunidade educacional e o meio social.

O estágio no ensino secundário é o terceiro módulo de formação, no que é conhecido como o mestrado em ensino secundário obrigatório e ensino médio, formação profissional e ensino de línguas. Os dois módulos anteriores são formação geral (por exemplo, disciplinas genéricas em educação: psicologia, educação e sociologia) e outro módulo específico (por exemplo, orientado para a área do conhecimento da especialização). O estágio escolar secundário é desenvolvido nos Centros de Ensino Secundário, Formação Profissional e Ensino de Línguas do distrito universitário correspondentes à Universidade de Salamanca. O objetivo fundamental do estágio é que os alunos conheçam, sob a supervisão de um Tutor Secundário, o funcionamento de um centro educacional e ponham em prática os ensinamentos recebidos nas disciplinas teóricas do mestrado (GUÍA DEL PRÁCTICUM, 2018b).

Os dois principais objetivos seriam: 1. Conhecer o ambiente escolar com base na abordagem e experiência direta. 2. Familiarize-se com os comportamentos e atitudes dos alunos das etapas educacionais ligadas ao seu ensino. O estágio é dividido em dois: (a) estágio de observação (60 horas letivas): dedicado a analisar e observar a prática docente de uma sala de aula secundária; e (b) estágio prático (60 horas letivas) cuja missão é assumir algumas horas de docência de uma ou várias salas de aula do ensino médio.

Em última análise, a formação inicial de professores na Espanha, como outros países, tem um duplo caráter disciplinar e profissionalizante. Disciplinar em relação ao currículo de formação ministrado nas universidades a partir do ensino de disciplinas específicas sobre educação, psicologia e sociologia. E profissionalizante em termos do 
treinamento prático recebido por algumas das faculdades nas escolas de educação infantil, primária e secundária. Essa combinação garante que os alunos tenham um conhecimento teórico e prático sobre a profissão docente, embora tenham começado a reivindicar a necessidade de preparação prática com mais presença e mais créditos nos programas de formação docente.

Tendo evidenciado, brevemente, a fundamentação que lastreia nossa prática de formação docente, no IFSP e USAL, fica a esperança de que tais modos de fazer sejam revisados, criticados e melhorados no futuro. Afinal, a construção do conhecimento e das práticas de formação de professores deve ser encarada como um perpétuo moto-contínuo. Isso, de certa maneira, foi tratado no primeiro artigo do dossiê, escrito por Herrán Gascón (2018). O autor desenvolve profundo exame epistemológico sobre a formação continuada de professores, a partir do que chama de enfoque radical, ou seja, de raiz. O artigo mergulha fundo no sentido da educação, considerando-a incompleta quando se trata apenas de uma formação acadêmica. Isso se traduz numa formação docente incompleta, que desconsidera a complexidade da educação como formação humana. Propõe, então, pensar em diversas conexões que se estabelece cotidianamente e que influenciam no modo de educar, desde a relação com colegas docentes, com estudantes e equipe diretiva, com as famílias e a comunidade no entorno de uma instituição de ensino, até as relações mais amplas, com o próprio sistema de educação, econômico e político, nacional e internacional. Propõe, ainda, que se considere o tempo histórico e vá além, compreendendo a docência como algo transcendental, pois nela se assenta o princípio do futuro.

Uma forma de pensar com profundidade a formação de professores aparece no segundo artigo do dossiê, proposto por Raimundo e Fagundes (2018). Os autores buscaram problematizar a formação continuada docentes por meio de uma reflexão provocada pelo materialismo histórico dialético, nas suas próprias palavras, "como base para a construção de conhecimentos de uma formação crítica e emancipadora" (p. 1935). Algo muito semelhante foi pensado no artigo seguinte, escrito por Barros e Vicentini (2018), pois, ao buscarem uma "epistemologia dialética" para a formação docente, esses autores também apresentam a necessidade de uma postura crítica, emancipatória, portanto, transformadora do contexto social em que o professor atua direta e cotidianamente.

Interessante proposta para formação docente foi pensada por Duarte e Moreira (2018), em Portugal, com estudantes de licenciatura, e por Pena, Toledo e Kramer (2018), no Brasil, com professoras atuantes na educação infantil. Os artigos quarto e quinto do dossiê, embora a partir de contextos distintos, ambos trabalharam com narrativas como 
forma de permitir que os professores, em formação ou exercício, percebessem a construção do seu próprio caminho profissional, percebendo-se como autores de sua jornada docente.

Com olhar específico para uma situação recorrente da sala de aula, Nogaro, Jung e Simões (2018) detalham, no sexto artigo do dossiê, a questão da atenção/desatenção dos estudantes frente à formação do docente para lidar com essa circunstância do processo ensino-aprendizagem. Segundo os autores, parece que a atenção é fundamental para aprender, tendo o professor papel fundamental nessa questão de manter o estudante atento. Para isso, há que se reconhecer os elementos internos e externos à sala de aula, que podem interferir negativamente na atenção dos estudantes, bem como estar ciente de como as técnicas de ensino e a tecnologia podem ser aliadas para superar esse desafio da prática docente.

Na sequência do dossiê, complexificando ainda mais a formação de professores, vimos Septimio, Mendes e Costa (2018) discutindo os saberes que faltam no processo formativo docente para o trabalho com estudantes com deficiência. Os autores oferecem caminhos para a reflexão, apresentado esse trabalho como um dos desafios mais contundentes da prática profissional.

É sabido que a conjuntura política interfere no trabalho docente. Não obstante, Costa, Souza e Cabral (2018) conseguem capturar tal interferência, ao postular, no oitavo artigo do dossiê, o controle do capital na formulação de políticas públicas e demais processos que tendem a limitar a ação dos professores. Isso é sintomático de um contexto político globalizado, o que acaba tendo forte influência nos pressupostos epistemológicos que sustentam todo trabalho de formação docente, inicial e/ou continuada.

Como uma forma de exemplificar o impacto da conjuntura política na formação docente, temos o artigo seguinte, de Santos e Maciel (2018). Ao analisar a epistemologia presente na formação inicial do professor alfabetizador, os autores encontraram lacunas consideráveis, dificultando a efetiva ação no ambiente escolar. São lacunas que dizem respeito ao currículo e a escolha dos conteúdos curriculares a serem ensinados, mas também a técnicas de ensino, particularmente o desenvolvimento de sequências didáticas. Com dificuldades em compreender "o que" e "como" ensinar, o trabalho como professor alfabetizador parece enfrentar dificuldades em atender ao exposto no Pacto Nacional pela Alfabetização na Idade Certa, o PNAIC, uma política pública brasileira de melhoria na "qualidade" da educação.

No décimo artigo do dossiê, vimos Soffner e Kirsch (2018) discutindo a perspectiva epistemológica de um programa de pós-graduação em educação. O próprio programa, o 
que dá uma dimensão subjetiva fundamental para a análise que propõem, afinal, buscam escarafunchar o sentido de formação docente a partir do próprio trabalho formativo que realizam. Se a pós-graduação não é o lugar da formação inicial ou continuada de professores, as pesquisas nela realizadas são indispensáveis para nortear práticas, políticas, teorias e, portanto, estabelecer novas ou fortalecer as já sedimentadas epistemologias.

Por fim, o último artigo do dossiê retrata a epistemologia para a formação docente no IFSP Itapetininga, lastreada pelo empirismo, conforme aprendido pela experiência educativa desenvolvida durante décadas de militância no chão da escola por Célestin Freinet (FORTUNATO, 2018a).

Essa constelação de temas é apenas parte de um todo muito mais amplo e complexo da epistemologia da formação de professores. O que se espera é que isso tenha sido evidenciado e que a epistemologia seja efetivamente compreendida como algo fundante da carreira docente, a qual deve ser revisitada amiúde por aqueles que são responsáveis pela formação de professores.

\section{REFERÊNCIAS}

ABBAGNANO, N. Dicionário de Filosofia. Trad. Alfredo Bosi. 5 ed. São Paulo: Martins Fontes, 2007.

ANGUITA, R. Algunas claves de la historia de la formación del profesorado en España para comprender el presente. Revista Universitaria de Formación del Profesorado, v. 30, p. 97-109, 1997.

AZCÁRATE, P. El diseño curricular en la formación didáctico matemática de los maestros. II Simposio sobre el currículo en la formación de profesores en el área de didáctica de las matemáticas de la Universidad de León: León: Actas..., 1997. p. 105-123.

BARROS, M. S. F.; VICENTINI, D. A epistemologia dialética na atividade pedagógica: realidade e possibilidade na formação do professor da infância. Revista Ibero-Americana de Estudos em Educação, Araraquara, v. esp. n. 3, p. 1952-1963, dez., 2018.

COSTA, M. C. S.; SOUZA, M. B.; CABRAL, M. C. R. A epistemologia da formação de professores materializada por meio dos organismos multinacionais. Revista IberoAmericana de Estudos em Educação, Araraquara, v. esp. n. 3, p. 2041-2053, dez., 2018.

CUNHA, C. R.; FORTUNATO, I. 50 Anos dedicados à pedagogia Freinet: um encontro com Rosa Maria Whitaker Sampaio. Revista Ibero-Americana de Estudos em Educação, Araraquara, v. 12, n. esp. p. 554-563, 2017.

CUNHA, M. I. da. O tema da formação de professores: trajetórias e tendências do campo na pesquisa e na ação. Educ. Pesqui., São Paulo, v. 39, n. 3, p. 609-625, 2013. 
DINIZ-PEREIRA, J. E. A construção do campo da pesquisa sobre formação de professores. Educação e Contemporaneidade, Salvador, v. 22, n. 40, p. 145-154, 2013.

DUARTE, P.; MOREIRA, A. I. epistemologia na profissão docente: a perspectiva dos professores em formação sobre formação inicial, supervisão pedagógica e identidade profissional. Revista Ibero-Americana de Estudos em Educação, Araraquara, v. esp. n. 3, p. 1964-1994, dez., 2018.

FALCHI, L.; FORTUNATO, I. Simulador phet e o ensino da tabuada na educação básica: relato de experiência. Política e Gestão Educacional, Araraquara v. 22, n. 1, p. 439-452, 2018.

FORTUNATO, I. A epistemologia da formação docente: o que se pode aprender com o empirismo de Freinet. Revista Ibero-Americana de Estudos em Educação, Araraquara, v. esp. n. 3, p. 1995-2007, dez., 2018.

FORTUNATO, I. A didática na formação inicial de professores: relato de experiência. Revista Ibero-Americana de Estudos em Educação, Araraquara, v. 13, n. 1, p. 269-276, $2018 b$.

FORTUNATO, I. Um curso de formação continuada de professores como lócus de pesquisa-ação: relato de experiência. Estreiadiálogos, Braga, v. 3, n. 1, 2018. [no prelo]

FORTUNATO, I. Reasons to consider Célestin Freinet's pedagogy still current. Revista Ibero-Americana de Estudos em Educação, Araraquara, v. 12, n. esp. p. 550-553, 2017.

FORTUNATO, I. 50 Anos sem Célestin Freinet, 500 Anos de Retrocesso das Práticas Escolares. Journal for Educators, Teachers and Trainers, Granado, v. 7, n. 1, p. 174181, 2016a.

FORTUNATO, I. Aprendendo com Célestin Freinet: o passado ainda é presente. Tendencia Pedagógicas, Madrid, v. 27, n. 1, p. 251-258, $2016 \mathrm{~b}$.

FORTUNATO, I.; CUNHA, C. R.; TEMPLE, C. Célestin Freinet's pedagogical invariants: a pathway to free and collaborative school education. Quaderni di didattica della scrittura, v. 26, n. 2, p. 44-51, 2016.

FÜLLER, F. F. Concerns of teachers: a developmental conceptualization. American Educational Research Journal, Washington (DC), v. 6, n. 2, p. 207- 226, 1969.

GUÍA DEL PRACTICUM en los grados de maestro. 2018a. Universidad de Salamanca. Disponível em: http://www.usal.es/grado-en-maestro-en-educacion-primaria-facultad-deeducacion. Acesso em: 14 out. 2018.

GUÍA DEL PRACTICUM en el Máster Universitario en Profesor de Educación Secundaria. 2018b. Disponível em: http://www.usal.es/master-secundaria. Acesso em: 14 out. 2018. 
HERRÁN GASCÓN, A. Algunos fundamentos sobre la formación continua del professorado desde el enfoque radical e inclusivo. Revista Ibero-Americana de Estudos em Educação, Araraquara, v. esp, n. 3, p. 1896-1934, dez., 2018.

IMBERNÓN, F. La formación del profesorado: ciertas confusiones y algunas evidencias. Aula de Innovación Educativa, v. 62, p. 40-42, 1997.

JAPIASSU, H. F. Introdução ao pensamento epistemológico. 5 ed. Rio de Janeiro: Francisco Alves Editora, 1988.

LADD H. F. Teacher Labor Markets in Developed Countries. Excellence in the Classroom, v. 17, n. 1, p. 201-217, 2007.

LIBÂNEO, J. C. Didática. 34 reimp. São Paulo: Cortez, 1994.

MENA, J.; CLARKE, A. Eliciting Teachers' Practical Knowledge through Mentoring Conversations in Practicum Settings. In: TILLEMA, H.; WESTHUIZEN, G. J. van der; SMITH, K. (org.) Mentoring for Learning: "Climbing the Mountain". Rotterdam: Sense Publishers, 2015. p. 47-78.

MENA, J.; RODRÍGUEZ, M.; HUBBAL, H.; CLARKE, A. La supervisión en el practicum bajo un enfoque multidisciplinar. In: Conferência ISATT: formação e trabalho docente na sociedade da aprendizagem, 2014, Braga. Anais eletrônicos... Braga: Universidade do Minho, 2014.

MENA, J.; HENNISSEN, P.; LOUGHRAN, J. Developing pre-service teachers' professional knowledge of teaching: the influence of mentoring. Teaching and Teacher Education, v. 66, p. 47-59, 2017.

MENA, J. La formación del profesorado, la mentoría, y el conocimiento profesional docente en el prácticum del grado de maestro de Educación Primaria. Trabajo para promoción docente no publicado. Universidad de Salamanca, 2016. (mimeo)

NOGARO, A.; JUNG, H. S.; SIMÕES, E. M. S. O que representa a atenção para a epistemologia da aprendizagem na contemporaneidade? - a percepção docente. Revista Ibero-Americana de Estudos em Educação, Araraquara, v. esp. n. 3, p. 2026-2040, dez., 2018.

PENA, A.; TOLEDO, L.; KRAMER, S. "Eu fiz um esquecimento do meu passado de professora": memória, narrativa e experiência como caminho epistemológico na formação de professores. Revista Ibero-Americana de Estudos em Educação, Araraquara, v. esp. n. 3, p. 2008-2025, dez., 2018.

PILETTI, N. Didática Geral. 23 ed. São Paulo: Ática, 2004.

PIMENTA, S. G. (org.) Didática e formação de professores: percursos e perspectivas no Brasil e em Portugal. $3^{\text {a }}$ ed. São Paulo: Cortez, 2000. 
RAIMUNDO, J.A.; FAGUNDES, M. A epistemologia da práxis como fenômeno formador do/a docente: um caminho possível? Revista Ibero-Americana de Estudos em Educação, Araraquara, v. esp. n. 3, p. 1935-1951, dez., 2018.

ROMANOWSKI, J. P. Tendências da pesquisa em formação de professores. Atos de pesquisa em educação, Blumenau, v. 8, n. 2, p.479-499, 2013.

SANTOS, C.; MACIEL, M. A formação docente e as (in) compreensões epistemológicas: revelações do PNAIC. Revista Ibero-Americana de Estudos em Educação, Araraquara, v. esp. n. 3, p. 2071-2086, dez., 2018.

SEPTIMIO, C.; MENDES, G. M. L.; COSTA, G. D. da. Habitantes temporários: O pressuposto epistemológico do (não) saber docente e a inventividade. Revista IberoAmericana de Estudos em Educação, Araraquara, v. esp. n. 3, p. 2054-2070, dez., 2018.

SOFFNER, R. K.; KIRSCH, D. B. Formação do professor-pesquisador: a importância da fundamentação epistemológica. Revista Ibero-Americana de Estudos em Educação, Araraquara, v. esp. n. 3, p. 2087-2099, dez., 2018.

TESSER, G. J. Principais linhas epistemológicas. Educar, Curitiba, n. 10, p. 91-98, 1995.

ZEICHNER, K. New epistemologies in teacher education. Rethinking the connections between campus courses and practical experiences in teacher education at the university. Interuniversity Journal of Teacher Education, v. 68, n. 24, p. 123-150, 2010,

\section{Como referenciar este artigo}

FORTUNATO, Ivan.; MENA, Juanjo. Sobre a epistemologia da formação de professores. Revista Ibero-Americana de Estudos em Educação, Araraquara, v. esp. n. 3, p. 18811895, dez., 2018. E-ISSN: 1982-5587. 10.21723/riaee.unesp.v13.iesp3.dez.2018.11900.

Submetido em: 10/11/2018

Aprovado em: 30/11/2018 